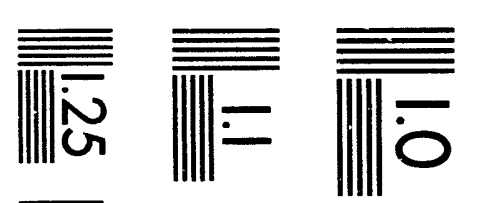

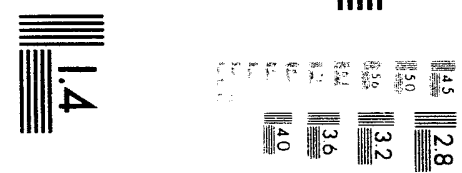

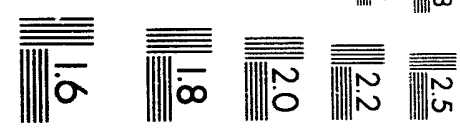



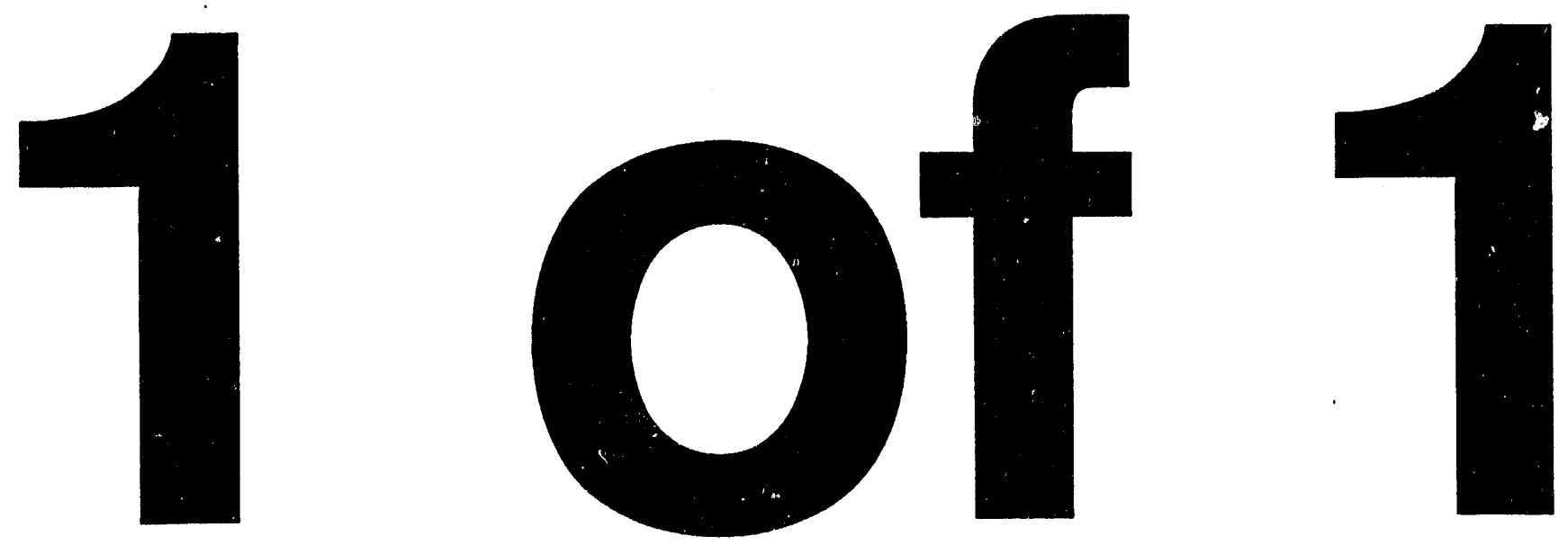


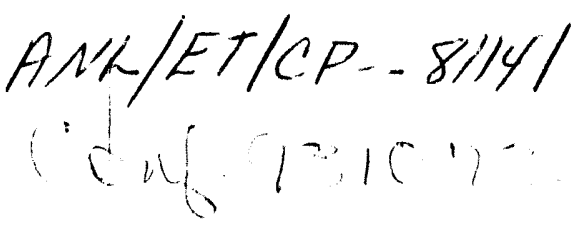

\title{
RECENT DEVELOPMENTS IN PROCESSING HTS SILVER-CLAD BI-2223 TAPES, COIS AND TEST MAGNETS
}

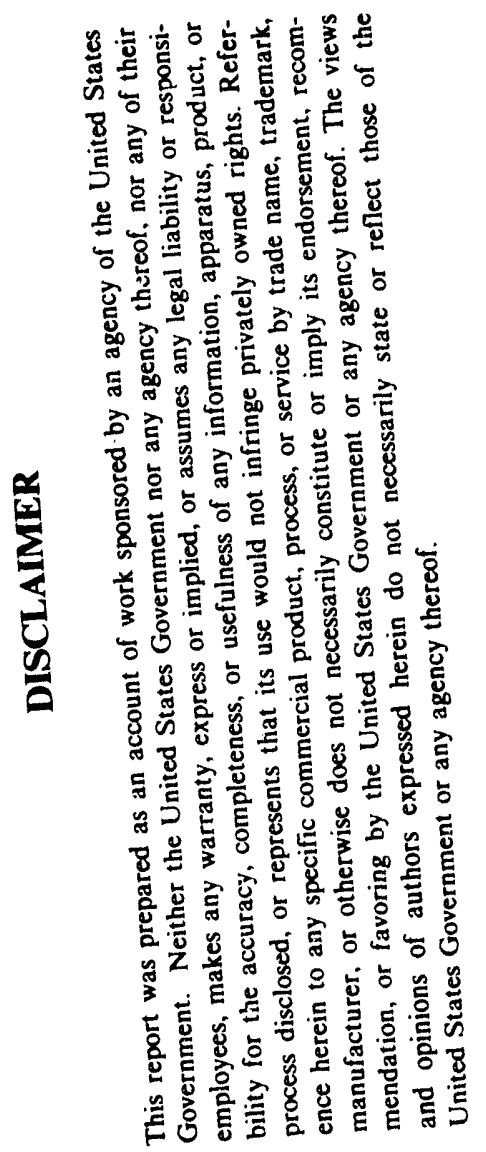

\author{
P. Haldar, J.G. Hoehn, Jr. \\ Intermagnetics General Corporation \\ Guilderland, NY 12084 \\ L.R. Motowidlo \\ IGC Advanced Superconductors, Inc. \\ Waterbury, CT 06704 \\ U. Balachandran \\ Energy Technology Division \\ Argonne National Laboratory \\ Argonne, IL 60439 \\ Y. Iwasa, M. Yunus \\ Francis Bitter National Magnet Laboratory, \\ Massachusetts Institute of Technology \\ Cambridge, MA 02139 \\ October 1993

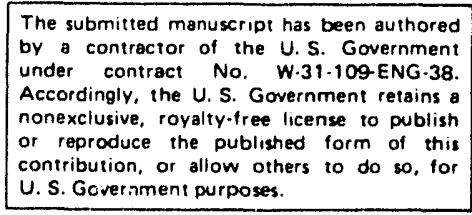

Invited paper for submission to proceedings of the6th International Symposium on Superconductivity, Hiroshima, Japan October 25-29, 1993.

*Work at Argonne National Laboratory and part of work at Intermagnetics General Corporation is supported by the U.S. Department of Energy (DOE), Energy Efficiency and Renewable Energy, as part of a DOE program to develop electric power technology, under Contract W-31-109-Eng-38. Part of the work at Francis Bitter National Magnet Laboratory (FBNML) is also supprorted by the U.S. Department of Energy (DOE), Energy Efficiency and Renewable Energy, for the same DOE program. The FBNML is supported by the National Science Foundation. 


\title{
RECENT DEVELOPMENTS IN PROCESSING HTS SILVER-CLAD BI-2223 TAPES, COILS AND TEST MAGNETS
}

\author{
P. HALDAR ${ }^{1}$, J.G. HOEHN, JR. ${ }^{1}$, L.R. MOTOWIDLO ${ }^{2}$, U. BALACHANDRAN ${ }^{3}$, \\ Y. IWASA 4 AND M. YUNUS 4 \\ 1 Intermagnetics General Corporation \\ Guilderland, NY 12084 \\ 2IGC Advanced Superconductors, Inc. \\ Waterbury, CT 06704 \\ ${ }^{3}$ Energy Technology Division \\ Argonne National Laboratory \\ Argonne, Il 60439 \\ ${ }^{4}$ Francis Bitter National Magnet Laboratory, \\ Massachusetts Institute of Technology \\ Cambridge, MA 02139
}

\begin{abstract}
Considerable progress has been made in fabricating $\mathrm{Bi}-2223$ high temperature superconductor (HTS) wires and tapes with high critical current densities that are attractive for electric power and high-field magnet applications. Powder-in-tube processed silver-clad $\mathrm{Bi}-2223$ short tape samples, small coils and test magnets have been fabricated and measured at liquid nitrogen $(77 \mathrm{~K})$, pumped liquid nitrogen $(64 \mathrm{~K})$, liquid neon $(27 \mathrm{~K})$ and liquid helium $(4.2 \mathrm{~K})$ temperatures. Optimization of thermo-mechanical process parameters have yielded $\mathrm{J}_{\mathrm{c}}$ 's in the superconducting core $>4.0 \times 10^{4} \mathrm{~A} / \mathrm{cm}^{2}$ at $77 \mathrm{~K}$, zero field and $>2.0 \times 10^{5} \mathrm{~A} / \mathrm{cm}^{2}$ at $4.2 \mathrm{~K}$, zero field. Long lengths (up to $70 \mathrm{~m}$ ) of mono-core conductors were fabricated and tested to carry significant amounts of current $\left(23 \mathrm{~A}, \sim 15,000 \mathrm{~A} / \mathrm{cm}^{2}\right.$ ) at liquid nitrogen temperature. Recent test magnets assembled from pancake wound coils were measured to generate magnetic fields as igh as 2.6, 1.8 and 0.36 Tesla at $4.2 \mathrm{~K}, 27 \mathrm{~K}$ and $77 \mathrm{~K}$ respectively. These results show promise towards practical utilization of HTS materials.

\section{INTRODUCTION}

The high temperature superconductors (HTS), particularly silver-sheathed Bi2223 made by the conventional powder-in-tube (PIT) approach, provide the potential of operating electric power devices and high-field magnets at temperatures (above $4.2 \mathrm{~K}$ ) and fields (above $20 \mathrm{~T}$ ) heyond the current capability of low temperature superconductors in addition to low-field applications at liquid nitrogen temperature. This is possible if long lengths of HTS conductor with high current densities can be fabricated economically on an industrial scale. In this paper we report critical current data for long lengths of the composite silver-sheathed composite conductors. The long lengths have also been processed, wound into small pancake coils, and used to construct test magnets. The critical current data of a test magnet at liquid nitrogen $(77 \mathrm{~K})$, pumped liquid nitrogen (64 $\mathrm{K})$, liquid neon $(27 \mathrm{~K})$, and liquid helium $(4.2 \mathrm{~K})$ are also reported.
\end{abstract}




\section{EXPERIMENTAL}

Long lengths of silver-clad $\mathrm{Bi}-2223$ HTS tapes were fabricated by the powder-intube technique as described earlier. ${ }^{3-4}$ Pre-reacted precursor powders were initially prepared from a mixture of high purity (>99.99\%) Bi, $\mathrm{Pb}, \mathrm{Sr}, \mathrm{Ca}$ and $\mathrm{Cu}$ oxides and carbonates. These were carefully mixed, heat treated, ground, and packed into high-purity silver tubes. The packed billets were lightly swaged, drawn through a series of dies, and then rolled to final size. A series of intermediate heat teatments were performed between 800 to $840^{\circ} \mathrm{C}$ to enable growth and alignment of the $\mathrm{Bi}-2223$ phase in the tape core. Long $(>30 \mathrm{~m})$ monofilament tapes have been processed this way. Short samples were cut from the long lengths and subjected to an additional series of uniaxial pressing and heat treating operations.

Test magnets was made by stacking and connecting in series a set of double pancake coils, each double-pancake coil set made by the 'wind-and-react' approach. Each pancake coil was comprised of three to five lengths of monofilament tape, co-wound in parallel to form a larger monolith conductor with ceramic insulation seperating each turn. Two coils wound on a single form were seperated by ceramic insulation and heat treated together to make a set of double-pancake. Several of the double-pancakes were stacked to form the test magnet. Epoxy resin provided the necessary structural strength and rigidity.

Long lengths of HTS tape (up to $70 \mathrm{~m}$ ) were characterized by the four-probe technique by spirally winding them on large mandrels and immersing them in liquid nillogen $(77 \mathrm{~K})$. Pancake coils were tested induvidually before and after assembling them iıiu test magnets. Voltage taps were placed at the ends of each coil. The test magnet, placed in a cryostat, was positioned in the bore of a water-cooled magnet. The central axial field generated by each magnet pointed in the same direction. Critical currents of the test magnet were measured at $4.2 \mathrm{~K}$ (liquid helium in the crysostat), at $27 \mathrm{~K}$ (liquid neon in the cryostat), 77 and $64 \mathrm{~K}$ (liquid nitrogen in the cryostat) for background fields up to $12 \mathrm{~T}$. The criterion for critical current was $1 \mu \mathrm{V} / \mathrm{cm}$ and critical current densities $\left(J_{c}\right.$ 's) were determined for the superconducting and overall cross-sectional areas. Earlier we had reported 5 measurements on a similar pancake wound magnet that generated a self-field of $1.0 \mathrm{~T}$ at $4.2 \mathrm{~K}$. Detailed measurements in fields up to $14.5 \mathrm{~T}$ and liquid neon $(27 \mathrm{~K})$ were also reported. Since then improvements in conductor performance and coil winding techniques have enabled the construction of HTS magnets that generate fields as high as $2.6 \mathrm{~T}$ at $4.2 \mathrm{~K}$. Characteristics of these recent magnets and tapes are described in this paper.

\section{RESULTS AND DISCUSSION}

Short tape samples ( 3.5 to $4.0 \mathrm{~cm}$ in length) that had been subjected to several cycles of uniaxial pressing and heat treatment always carry the highest currents. Values above $40 \mathrm{~A}$ were typically attained at liquid nitrogen temperature, with the highest being 51 A for samples that were subjected to 3 to 4 cycles of uniaxial pressing and heat treatment. These corresponded to superconductor core $\mathrm{J}_{\mathrm{c}}$ 's of $\sim 45,000 \mathrm{~A} / \mathrm{cm}^{2}$ and overall $\mathrm{J}_{\mathrm{c}}$ 's of $9,000 \mathrm{~A} / \mathrm{cm}^{2}$ for samples with a $20 \%$ superconductor (SC) fraction. More recent results on as rolled samples (as opposed to pressed) with a larger SC fraction of $27 \%$ were measured to carry currents as high as $51 \mathrm{~A}$, with representative core $\mathrm{J}_{\mathbf{c}}$ 's approaching $\sim 30,000 \mathrm{~A} / \mathrm{cm}^{2}$ and overall $\mathrm{J}_{\mathrm{c}}$ 's $\sim 8,000 \mathrm{~A} / \mathrm{cm}^{2}$. For true comparison, however, we have provided results for short tapes and long lengths of composites, with similar superconductor fractions, in Table 1 . These tapes were processed by a two-cycle cold-rolling and heat treatment operation. Overall, or engineering, $J_{c}$, determined from the cross-sectional area given by thickness times width (not considering taper of the tape edges), together with the superconductor fraction $(24 \%)$ is also indicated in Table 1. 
Note that the current carrying ability of the long lengths are still significantly lower than that achieved in short samples.

Table 1. Critical current densities at $77 \mathrm{~K}$ of selected short and long tapes fabricated at IGC.

\begin{tabular}{lcccc}
\hline & $\begin{array}{l}I_{C} \\
(A)\end{array}$ & $\begin{array}{l}\text { Core } J_{C} \\
\left(\mathrm{~A} / \mathrm{cm}^{2}\right)\end{array}$ & $\begin{array}{l}\text { Overall } J_{C} \\
\left(\mathrm{~A} / \mathrm{cm}^{2}\right)\end{array}$ & $\begin{array}{l}\text { SC } \\
(\%)\end{array}$ \\
\hline $\begin{array}{l}\text { Short Sample } \\
\text { (Rolled) }\end{array}$ & 33 & $\sim 21,000$ & 5,000 & 24 \\
$\begin{array}{l}\text { Long length } \\
(34 \mathrm{~m})\end{array}$ & 16 & $\sim 11,000$ & 2,500 & 24 \\
$\begin{array}{l}\text { Long length } \\
(70 \mathrm{~m})\end{array}$ & 23 & $\sim 15,000$ & 3,500 & 24 \\
\hline
\end{tabular}

Figure 1 shows a photograph of a recent test magnet, assembled by stacking five double-pancake coils that generated a maximum self-field of $2.6 \mathrm{~T}$ at $4.2 \mathrm{~K}$. The dimensions and pertinent parameters of the magnet, the critical current data and maximum and minimum fields are presented in Table 2 . At $77 \mathrm{~K}$ a Hall probe was placed in the bore of the magnet to obtain its field constant and field generated at the midplane. At $4.2 \mathrm{~K}$ the field generated was calculated from the critical current measured at liquid helium and the field constant.

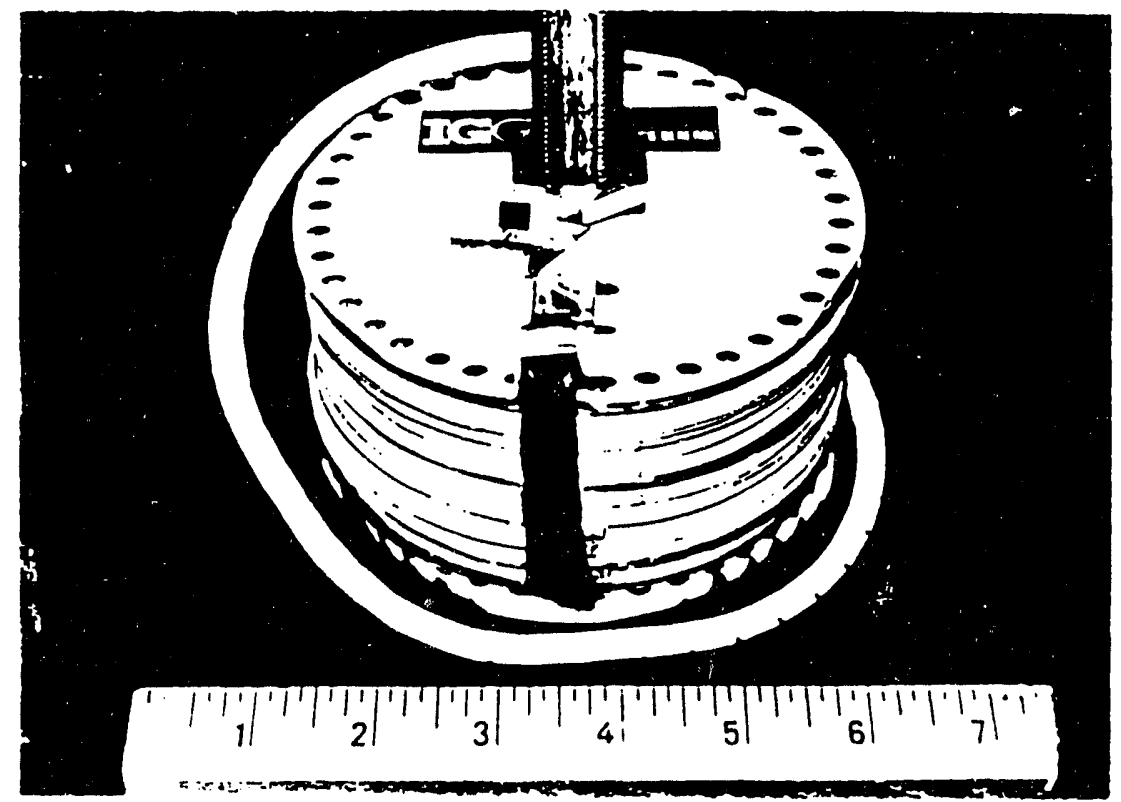

Figure 1. Photograph of a recent test magnet constucted at IGC that generated a maximum self-field of $2.6 \mathrm{~T}$ at $4.2 \mathrm{~K}$ and $0.36 \mathrm{~T}$ at $77 \mathrm{~K}$. 
Table 2. Parameters, critical current and field generated data of a recent test magnet

Winding Inner diameter $(\mathrm{cm})$

Winding Outer diameter $(\mathrm{cm})$

Coil Height $(\mathrm{cm}) \quad 6.35$

No. of co-wound tapes per pancake

Total length of tape in magnet (m) 480

Total no. of turns in the magnet 700

Overall winding cross-section $\left(\mathrm{cm}^{2}\right)$

No. of pancake coils 10

Magnet constant (Gauss/Amp) $\quad 111.2$

$77 \mathrm{~K}$ Measured

$\begin{array}{llll}\text { Ic Max: } & 32 \mathrm{~A} & \text { Bo Max: } & 0.36 \mathrm{~T} \\ \text { Ic Min: } & 19 \mathrm{~A} & \text { Bo Min: } & 0.21 \mathrm{~T}\end{array}$

Ic Min: $\quad 19 \mathrm{~A} \quad$ Bo Min: $0.21 \mathrm{~T}$

$27 \mathrm{~K}$ (Extrapolated)

$\begin{array}{llll}\text { Ic Max: } & 160 \mathrm{~A} & \text { Bo Max: } & 1.80 \mathrm{~T}\end{array}$

\section{$4.2 \mathrm{~K}$ (Measured)}

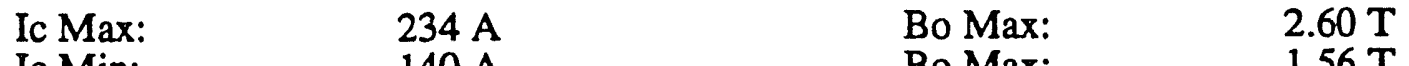

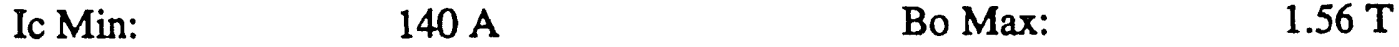

The liquid neon $(27 \mathrm{~K}$ ) data was extrapolated using tests done on similar HTS magnets. Each of the ten pancake coils that comprised the test magnet was monitored and since each performed differently, critical current and field generated data corresponding to the maximum and minimum are reported. The maximum critical current corresponds to a single pancake coil in the assembly that carried the highest $I_{\mathcal{C}}$ while the minimum represents the coil that had the lowest critical current for the entire assembly. The maximum and minimum values of self-field were also determined using these values and the magnet field constant.

Figure 2 represents plots of the maximum and minimum central field generated by a recent test magnet vs background field at $4.2 \mathrm{~K}$ and $27 \mathrm{~K}$. This test magnet was similar in dimensions and characteristics to the one shown in Figure 1. However, it's critical currents were slightly lower. The field constant for this magnet was measured at $77 \mathrm{~K}$ to be 109.2 Gauss/Amp. At $4.2 \mathrm{~K}$ and $27 \mathrm{~K}$, without an applied background field, the maximum current carried was $167 \mathrm{~A}$ and $130 \mathrm{~A}$ respectively. This enabled it to generate a maximum field of $1.83 \mathrm{~T}$ and $1.43 \mathrm{~T}$ repectvely. At high background fields (up to $12 \mathrm{~T}$ ) the magnet assembly continues to generate significant self-fields as seen from Figure 2 . The values at $27 \mathrm{~K}$ are consistent with the expectation that a very small component of the $\mathrm{H}\rfloor$ orientation is seen by the tapes, enabling the magnet to maintain its superconducting behavior even in high fields. Similar background field dependence at $4.2 \mathrm{~K}$ and $27 \mathrm{~K}$ were achieved in an earlier test magnet. 5 


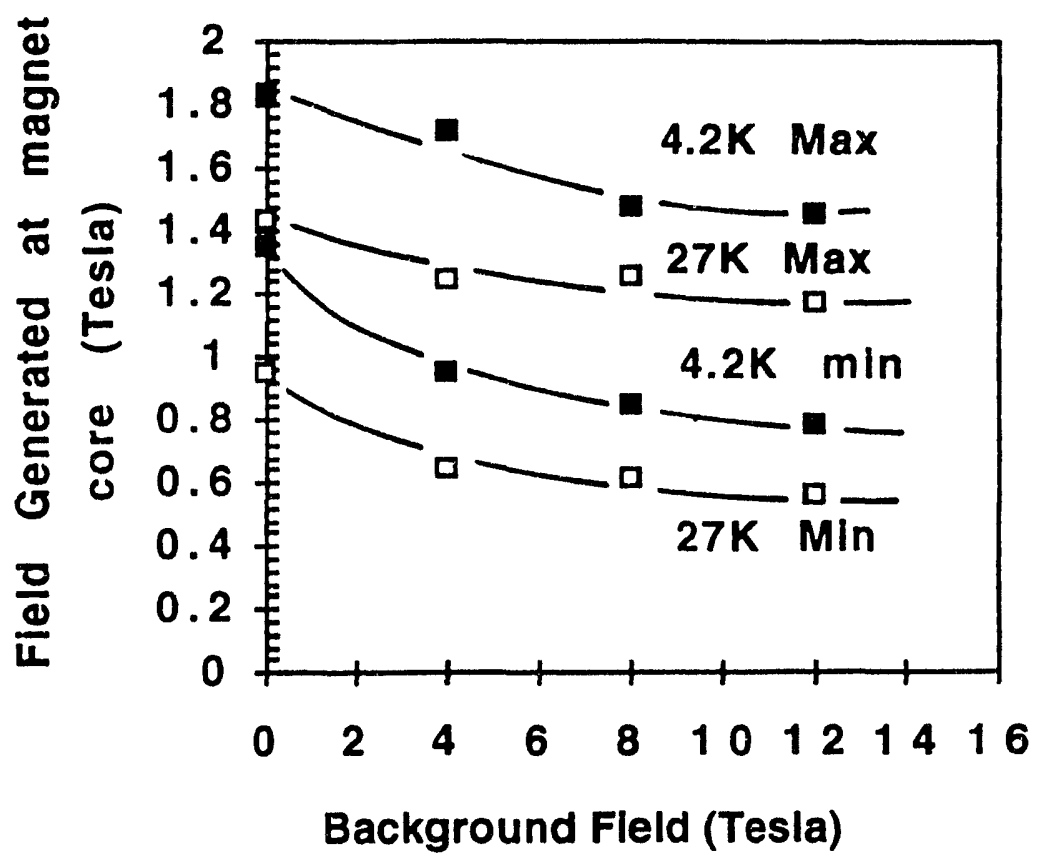

Figure 2. Maximim and Minimum values of an HTS test magnet center field vs. background field at liquid helium $(4.2 \mathrm{~K})$ and liquid neon $(27 \mathrm{~K})$

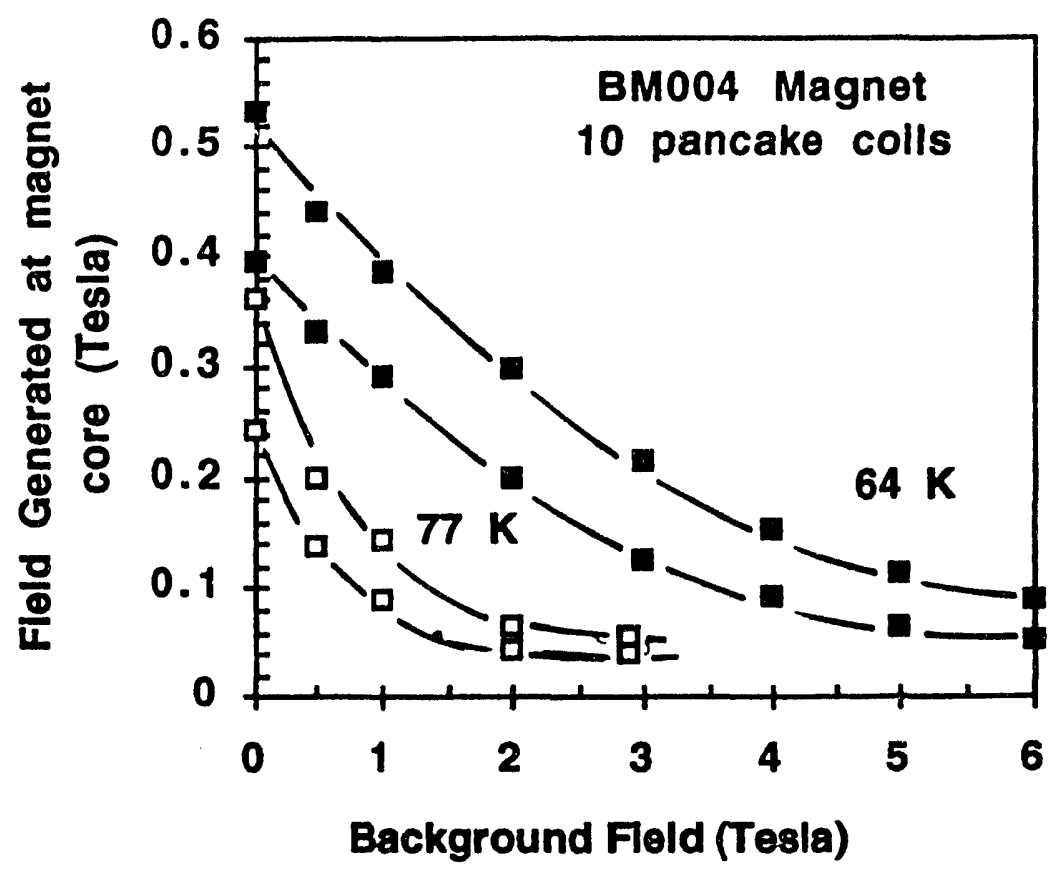

Figure 3. Maximim and Minimum values of an HTS test magnet center field vs. background field at liquid nitrogen $(77 \mathrm{~K})$ and pumped liquid nitrogen $(64$ $\mathrm{K})$ temperatures. 
Figure 3 represents plots of the maximum and minimum central field generated by the test magnet, indicated in Figure 2, vs background field at $77 \mathrm{~K}$ and 64 $\mathrm{K}$. At $77 \mathrm{~K}$ and $64 \mathrm{~K}$, without an applied background field, the maximum current carried was $32 \mathrm{~A}$ and $48 \mathrm{~A}$ respectively. This enabled it to generate a maximum field of $0.36 \mathrm{~T}$ and $0.53 \mathrm{~T}$ repectvely. At these higher temperatures it is interesting to observe the performance of the magnet in background fields. At $77 \mathrm{~K}$ a significant degradation in current carrying ability is seen. Infact, in applied fields up to $1.0 \mathrm{~T}$ the reduction is greater than $50 \%$. However, at $64 \mathrm{~K}$, for the first time, we report significant current carrying ability and field generation in background applied fields up to 2.0 Tesla. Moreover, the magnet assembly continues to carry current and generate self-fields in a background field at $6.0 \mathrm{~T}$ as seen from Figure 2. These results at 77 and $64 \mathrm{~K}$ are consistent with data reported earlier 6 for short tape samples where an order of magnitude improvements were shown in 2.0 Tesla applied fields.

The set of results presented here indicates that HTS materials are promising for high-field magnets and electric power devices operating at a temperature below $\sim 30 \mathrm{~K}$; operation at temperatures above $4.2 \mathrm{~K}$ could improve refrigeration efficiency and reliability. Low field applications (below 2.0 Tesla) can also be envisioned for temperatures up to $64 \mathrm{~K}$.

\section{ACKNOWLEDGEMENTS}

Work at Argonne National Laboratory and part of work at Intermagnetics General Corporation is supported by the U.S. Department of Energy (DOE), Energy Efficiency and Renewable Energy, as part of a DOE program to develop electric power technology, under Contract W-31-109-Eng-38. Part of the work at the Francis Bitter National Magnet Laboratory (FBNML) is also supported by the U.S. Department of Energy (DOE), Energy Efficiency and Renewable Energy for the same DOE program. The FBNML is supported by the National Science Foundation.

\section{REFERENCES}

1. K. Sato, T. Mikata, H. Mukai, M. Ueyama, T. Kato, T. Masuda, M. Nagata, K. Iwata and T. Misui, High-Jc silver sheathed Bi-based superconducting wire, IEEE Trans. Magn. 27, 1231 (1991).

2. Y. Yamacia, B. Obst and R. Flükiger, Microstructural study of $\mathrm{Bi}(2223) / \mathrm{Ag}$ tapes with Jc (77K, 0T) values of up to $3.3 \times 10^{4} \mathrm{~A} / \mathrm{cm}^{2}$, Supercond. Sci. Technol. 4, 165 (1991).

3. L. R. Motowidlo, E. Gregory, P. Haldar, J.A. Rice and R.D. Blaugher, Critical currents and processing of wound coils of Ag-sheathed $\mathrm{Bi}-2223$ high Tc tape: Microstructural and pinning effects, Appl. Phys. Lett. 59, 736 (1991).

4. P. Haldar, J.G. Hoehn, Jr., J.A. Rice and L.R. Motowidlo, Enhancement in critical current density of $\mathrm{Bi}-\mathrm{Pb}-\mathrm{Sr}-\mathrm{Ca}-\mathrm{Cu}-\mathrm{O}$ tapes by thermomechanical processing: Cold rolling versus uniaxial pressing, Appl. Phys. Lett. 60, 495 (1992).

5. P. Haldar, J.G. Hoehn, Jr., L.R. Motowidlo, U. Balachandran and Y. Iwasa, Fabrication and characteristics of a test magnet from HTS Bi-2223 silver-clad tapes, Adv. Cryogenic. Engg., in print.

6. P. Haldar, J.G. Hoehn,Jr., J.A. Rice, L.R. Motowidlo, U. Balachandran, C.A. Youngdahl, J.E. Tkaczyk and P.J. Bednarczyk, Fabrication and properties of highTc tapes and coils made from silver-clad Bi-2223 superconductors, IEEE Trans. Appl. Supercond. 3, 1127 (1993). 

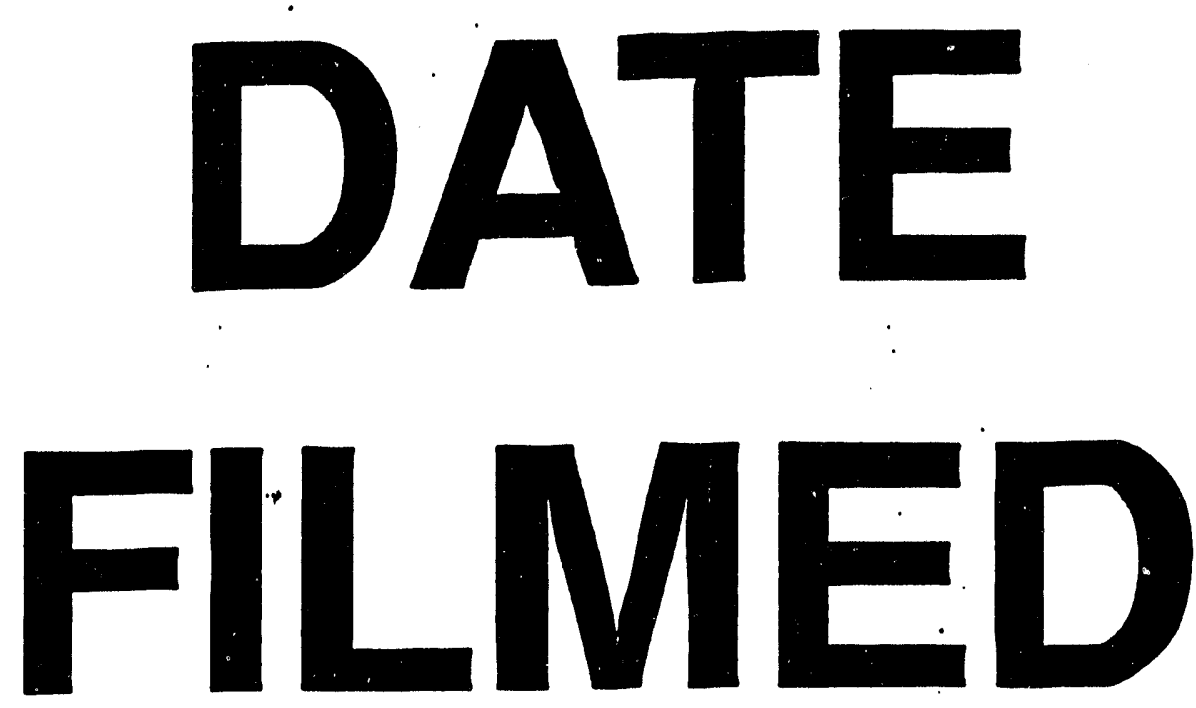

$12 / 27 / 93$
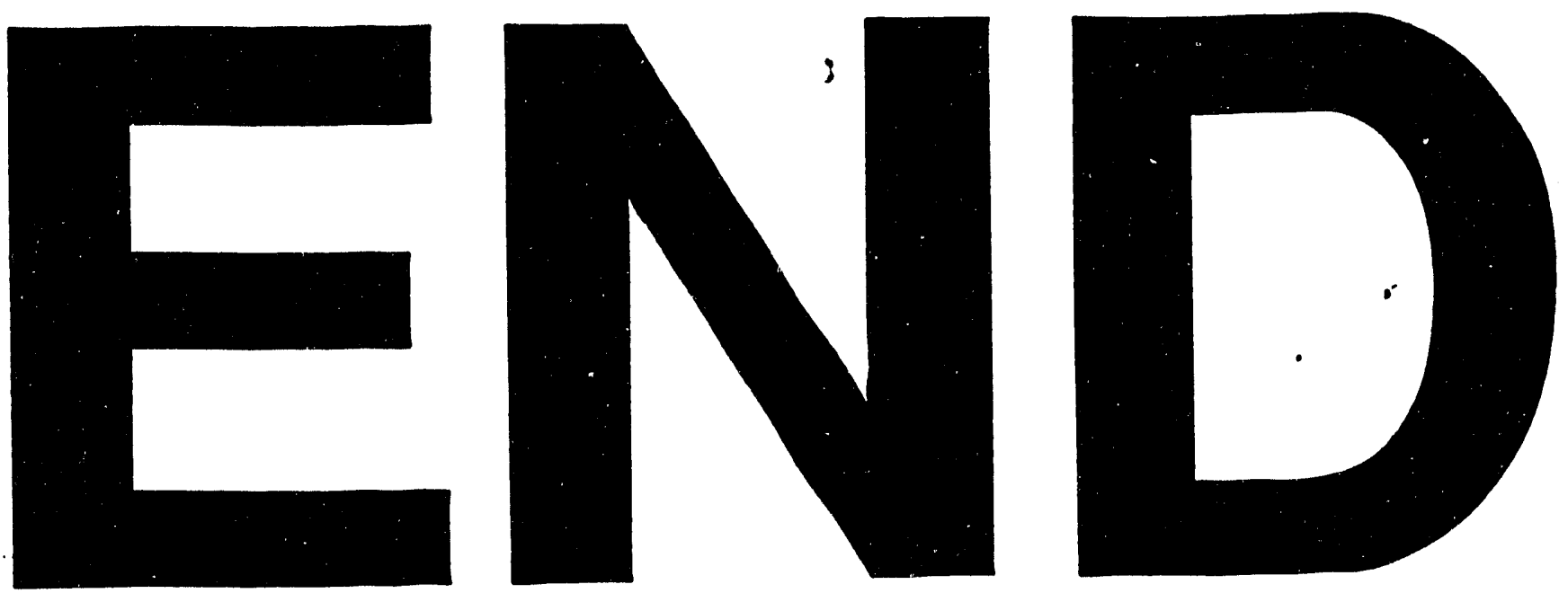
